\title{
Moisture variations over the past millennium characterized by Qaidam Basin tree-ring $\delta^{18} \mathrm{O}$
}

\author{
WANG WenZhi ${ }^{1,2}$, LIU XiaoHong ${ }^{1,2^{*}}$, XU GuoBao $^{1,2}$, SHAO XueMei $^{3}$, QIN DaHe ${ }^{1}$, \\ SUN WeiZhen ${ }^{1}$, AN WenLing ${ }^{1,2}$ \& ZENG XiaoMin ${ }^{1,2}$ \\ ${ }^{1}$ State Key Laboratory of Cryospheric Sciences, Cold and Arid Regions Environmental and Engineering Research Institute, \\ Chinese Academy of Sciences, Lanzhou 730000, China; \\ ${ }^{2}$ University of Chinese Academy of Sciences, Beijing 100049, China; \\ ${ }^{3}$ Institute of Geographical Sciences and Natural Resources Research, Chinese Academy of Sciences, Beijing 100101, China
}

Received January 26, 2013; accepted March 26, 2013; published online June 6, 2013

\begin{abstract}
High-resolution tree-ring $\delta^{18} \mathrm{O}$ chronologies covering the last millennium, although scarce, are essential in understanding patterns of climatic changes in the northeastern region of the Qinghai-Tibetan Plateau. For this study, a tree-ring $\delta^{18} \mathrm{O}$ chronology with a temporal resolution of 3-years was developed from the long-lived Qilian juniper (Sabina przewalskii Kom.), extending back in time to $\mathrm{AD} 991$. This long $\delta^{18} \mathrm{O}$ chronology was significantly correlated with the yearly $\delta^{18} \mathrm{O}$ in tree rings during the common period from 1800 to 2006, and was an effective proxy for relative humidity during the growing season. A low-frequency moisture pattern signified the occurrence of a slight drought during the Medieval Climate Anomaly, a marked occurrence of a wet period during the Little Ice Age, and a trend in increasing moisture levels, although lower than average, alongside the Twentieth Century warming trend. Comparisons to other hydroclimatic reconstructions indicate that this tree-ring $\delta^{18} \mathrm{O}$ chronology serves as a reliable paleo-humidity proxy for the Qaidam Basin as well as documenting details of past humidity levels in the region.
\end{abstract}

tree-ring $\delta^{18} \mathrm{O}$, moisture variation, medieval climate anomaly, little ice age, Qaidam Basin

Citation: Wang W Z, Liu X H, Xu G B, et al. Moisture variations over the past millennium characterized by Qaidam Basin tree-ring $\delta^{18} \mathrm{O}$. Chin Sci Bull, 2013, 58: 3956-3961, doi: 10.1007/s11434-013-5913-0

The Qinghai-Tibetan Plateau plays a key role in atmospheric circulation patterns over Asia, especially in relation to summer monsoon circulation owing to its high altitude, massive size, and critical geographical position between two climate regimes. Evidence suggests that the climate on the Plateau itself has also been responsive to recent global climate change [1]. To generate a better understanding of long-term climatic changes on the Qinghai-Tibetan Plateau, additional climatic data over longer timescales are required [2,3]. However, observed meteorological datasets for this vast and remote region are sparse, and most of what exists is limited in length to less than a century (beginning in about 1950).

Regional climate changes that affect hydrologic cycles

*Corresponding author (email: liuxh@1zb.ac.cn) are of critical scientific concern in the vulnerable and extremely arid Qaidam Basin, located in the northeastern Qinghai-Tibetan Plateau. Investigations related to long-term patterns in climatic variability in this region must therefore rely on high-resolution paleoclimatic records. A number of studies have provided an outline of the regional moisture regime during the past millennium based on lake sediments [4,5] and tree-ring widths [6-9] in and around the Qaidam Basin. They have offered important insights into climate change patterns at interannual to centennial timescales. Among these records, tree rings have the advantage of encompassing a wide geographic coverage, higher temporal resolution (seasonal to annual), absolute chronology, and higher overall reliability, and are therefore one of the easiest and most commonly used indices. However, tree-ring width series 
often obscure low-frequency signals as a result of standardization technique drawbacks used to remove age trends [10]. On the other hand, tree-ring stable isotope chronologies, especially those related to $\delta^{18} \mathrm{O}$, can record detailed climatic information that is both accurately dated and less affected by age effects [11], a growth effect caused by ${ }^{18} \mathrm{O}$ enrichment during the juvenile phase (often less than 30 years). Two millennium-long tree-ring $\delta^{18} \mathrm{O}$ chronologies have been previously established, both capturing precipitation variations between the western and southern boundaries of the Qinghai-Tibetan Plateau [12,13]. Although some millennium-long tree-ring width series have been developed for the northeastern boundary of the Plateau [6,7], a millennial treering $\delta^{18} \mathrm{O}$ chronology has not yet been constructed. In addition, although tree-ring width series have often been used to reconstruct precipitation variation [6,7], little is known regarding relative humidity in the Qaidam Basin over the past millennium.

Here, we present such a chronology that provides new evidence for regional moisture fluctuations over a period ranging from $\mathrm{AD} 991$ to $\mathrm{AD} 2010$. The chronology was derived from a 3-year temporal resolution $\delta^{18} \mathrm{O}$ series taken from tree rings of the long-lived Qilian juniper (Sabina przewalskii Kom.) and was validated against previously established annually-resolved $\delta^{18} \mathrm{O}$ in tree rings [14].

\section{Material and methods}

The study area is located in the northeastern part of the Qaidam Basin (Figure 1), where the mountains reach elevations higher than $4400 \mathrm{~m}$ a.s.l. The region's climate is under strong continental influence, characterized by long, cold,

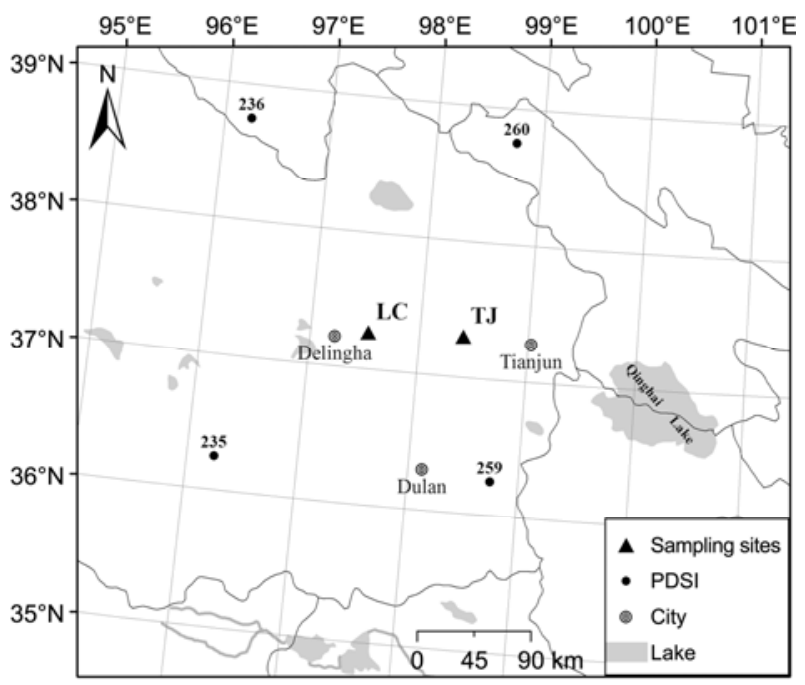

Figure 1 Location of tree-ring sampling sites. Also shown are the four points (codes: 235, 236, 259, and 260) used to reconstruct the Palmer Drought Severity Index (PDSI) in the region of the study area [9]. LC denotes the long-term $\delta^{18} \mathrm{O}$ chronology reconstructed for this study. TJ denotes the Tianjun $\delta^{18} \mathrm{O}$ chronology [14]. and dry winters. Mean annual temperature has been approximated at $3.8^{\circ} \mathrm{C}$ at the Delingha meteorological station $\left(37^{\circ} 22^{\prime} \mathrm{N}, 97^{\circ} 22^{\prime} \mathrm{E}, 2981.5 \mathrm{~m}\right.$ a.s.1.). Mean monthly temperature ranges from a low of $-11.5^{\circ} \mathrm{C}$ in January to a high of $16.7^{\circ} \mathrm{C}$ in July. Total annual precipitation averaged only 166 $\mathrm{mm}$ between 1956 and 2008, with up to $60 \%$ falling in summer (from June to August). The region is characterized by a desert steppe landscape. Its native vegetation consists of various desert and dry grassland plants, such as Artemisia spp., Haloxylon ammodendron, and Sympegma regelii. In the region's mountainous areas, sparsely distributed Qilian juniper trees grow on sunny and semi-sunny slopes where orographic effects result in above average precipitation.

Samples from 20 living Qilian juniper trees were collected from the northeastern Qaidam Basin $\left(37^{\circ} 16^{\prime} \mathrm{N}, 97^{\circ} 32^{\prime} \mathrm{E}\right.$, $4000 \mathrm{~m}$ a.s.1.) using 12-mm-diameter increment borers. It should be noted that this site has provided China's longest tree-ring width chronology to date (3585 years) [8]. Previous research suggests that a minimum sample core collection of four trees is required to build a robust tree-ring $\delta^{18} \mathrm{O}$ chronology on the Qinghai-Tibetan Plateau [11]. After crossdating to the regional ring-width chronology [7], four cores were selected for $\delta^{18} \mathrm{O}$ analysis, procured from four dominant juniper trees that highly correlated to the master chronology but only exhibited rare occurrences of missing rings or periods of extremely depressed growth. Because Qilian junipers grow very slowly, annual-resolved rings were difficult to separate. Thus, each core was carefully separated into 3-year blocks using a dissecting scalpel under a binocular microscope, after which samples were pooled from the same 3-year block group. The first 30 annual rings of each core were removed before pooling to avoid possible bias caused by juvenile effects. The $\alpha$-cellulose extraction followed procedures described in previous studies [14-16].

An approximate $0.14-0.16 \mathrm{mg}$ of $\alpha$-cellulose from each sample was loaded into silver capsules to determine isotopic ratios applying a High Temperature Conversion Elemental Analyzer (TC/EA) coupled with a Finnigan MAT 253 Mass Spectrometer (Thermo Electron Corporation, Bremen, Germany) at the State Key Laboratory of Cryospheric Sciences, Chinese Academy of Sciences (CAS). To ensure precision, $\delta^{18} \mathrm{O}$ analysis of each sample was repeated four separate times. After removing outliers (values greater than three times the standard deviation from the mean), mean values were calculated. The cellulose standard IAEA-CH-3 $\left(\delta^{18} \mathrm{O}=\right.$ $32.2 \%$ o was used to calibrate tree-ring $\delta^{18} \mathrm{O}$ measurements. Following this, measured $\delta^{18} \mathrm{O}$ values were referenced against the Vienna Standard Mean Ocean Water (VSMOW) value, and it was determined that the analytical error of repeated isotope measurements was better than $0.3 \%$ o $(=1 \sigma)$.

\section{Results and discussion}

The millennial $\delta^{18} \mathrm{O}$ chronology significantly correlated 
with the yearly $\delta^{18} \mathrm{O}$ chronology from the earlier Tianjun record [14] (Figure 2) for the period beginning in AD 1800. The Tianjun $\delta^{18} \mathrm{O}$ series was developed using eight or nine cores from select Qilian juniper trees, spanning from AD 1800 to 2006. The annual-resolution Tianjun $\delta^{18} \mathrm{O}$ series was averaged to yield 3 -year values before being correlated to this study's chronology (Figure 2(a)). A correlation coefficient of $r=0.61(P<0.001, n=69)$ was subsequently attained. Similarities between the two chronologies were also evident in high-frequency variations (i.e. those based on first-order differences) beginning in AD 1800, where $r=0.62(P<0.001$, $n=69$ ) between this study's chronology and the Tianjun chronology (Figure 2(b)). Coherence between the tree-ring $\delta^{18} \mathrm{O}$ series from the two sites suggests that the same climatic parameters force the degree of $\delta^{18} \mathrm{O}$ enrichment in the northeastern Qaidam Basin. Microclimates and microenvironments are nevertheless different in the two sampling sites, being $200 \mathrm{~km}$ distance apart. Moreover, the difference in altitude is approximately $400 \mathrm{~m}$. These geographic differences can, to a degree, influence discrimination of stable oxygen isotopes from which $\delta^{18} \mathrm{O}$ between the two sites would produce distinctive $\delta^{18} \mathrm{O}$ series [17]. However, differences caused by these different microenvironments were on the whole minor as they relate to the final tree-ring $\delta^{18} \mathrm{O}$ values because these different microenvironments belonged to the same climate regime.

Mechanistic models predict that climatic signals present in tree-ring cellulose $\delta^{18} \mathrm{O}$ are likely due to source water (i.e. mostly $\delta^{18} \mathrm{O}$ found in local precipitation) and transpiration
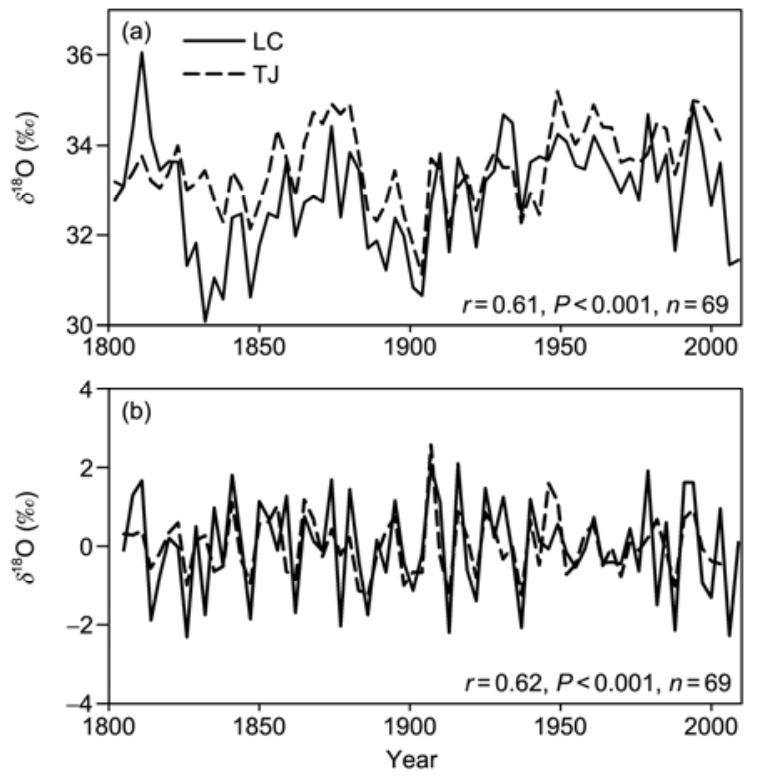

Figure 2 A comparison between the two $\delta^{18} \mathrm{O}$ chronologies for the Qaidam Basin from AD 1800 onwards. (a) Raw data; (b) high-frequency variation. LC denotes the $\delta^{18} \mathrm{O}$ chronology reconstructed for this study and TJ denotes the Tianjun $\delta^{18} \mathrm{O}$ chronology reconstructed by Xu et al. [14]. The Tianjun $\delta^{18} \mathrm{O}$ series was averaged to a temporal resolution of 3 years to facilitate comparisons between it and this study's results. effects (generally controlled by relative humidity in summer); however, the relative strength of these two effects on tree-ring $\delta^{18} \mathrm{O}$ largely depends on local climatic characteristics $[17,18]$. In the extremely arid inland region of Qaidam Basin, tree-ring $\delta^{18} \mathrm{O}$ values $(33.46 \%$ o $\pm 0.99 \%$ ) were higher than previously published data showed [14], suggesting evaporation is the important driver that raises the leaf water oxygen isotope ratio. The amount of evaporation depends on both stomatal conductance and the vapor pressure deficit, both of which are linked to relative humidity. Thus, at least in theory, tree-ring $\delta^{18} \mathrm{O}$ should reflect relative humidity in the growing season, during which time annual growth rings will form. Previous research has also shown that the annual-resolution cellulose $\delta^{18} \mathrm{O}$ series was negatively correlated with relative humidity $(r=-0.56, P<0.001)$ between July and August [14]. This provides independent evidence that the cellulose $\delta^{18} \mathrm{O}$ series for the Qaidam Basin is controlled by relative humidity in the growing season, and thus serves as an effective proxy for moisture variations during that season. However, in the growing season, the signal strength of relative humidity contained in the tree-ring $\delta^{18} \mathrm{O}$ series was weakened to some extent by oxygen exchange with xylem and soil water [18], which was used to record the Qaidam Basin temperature data [19]. Winter temperature data from previous Qinghai spruce tree-ring $\delta^{18} \mathrm{O}$ was recorded in the Qilian Mountains (a distance of approximately $350 \mathrm{~km}$ from the sites used for this study) [15]. Although these two regions fall within the same continental arid climate regime, the Qilian Mountain is wetter than the Qaidam Basin, resulting in less transpiration for the former. Species-specific response may also play a role in the recording of climate signals by tree-ring $\delta^{18} \mathrm{O}$. This study's ongoing investigation on high-resolution intra-annual variation in tree-ring $\delta^{18} \mathrm{O}$ can help to address $\delta^{18} \mathrm{O}$ climatic signals from different regions.

Based on past and present evidence, tree-ring $\delta^{18} \mathrm{O}$ can be regarded as an indicator of relative humidity during the growing season in the Qaidam Basin. For this study, extremely moist periods were defined as years with $\delta^{18} \mathrm{O}$ less than the mean minus one standard deviation $(-\sigma)$, and extremely dry periods were defined as years with $\delta^{18} \mathrm{O}$ greater than the mean plus one standard deviation $(+\sigma)$ (Figure 3(a)). From AD 991 to 2010, moist periods occurred from approximately AD 1061 to 1091,1346 to 1388,1604 to 1646,1733 to 1760,1832 to 1847 , and 1886 to 1913 . Dry periods occurred from AD 1172 to 1208,1301 to 1343 , 1481 to 1502,1784 to 1814 , and 1931 to 1961 . The mean duration of wet periods was 30.5 years versus 31.8 years for dry periods. Thus, both wet and dry periods persisted for periods that roughly ranged 30 years.

Throughout the millennial study period, three major climatic episodes took place. These were the Medieval Climate Anomaly (MCA), the Little Ice Age (LIA), and the warming trend of the Twentieth Century. Yang et al. [20] suggest 

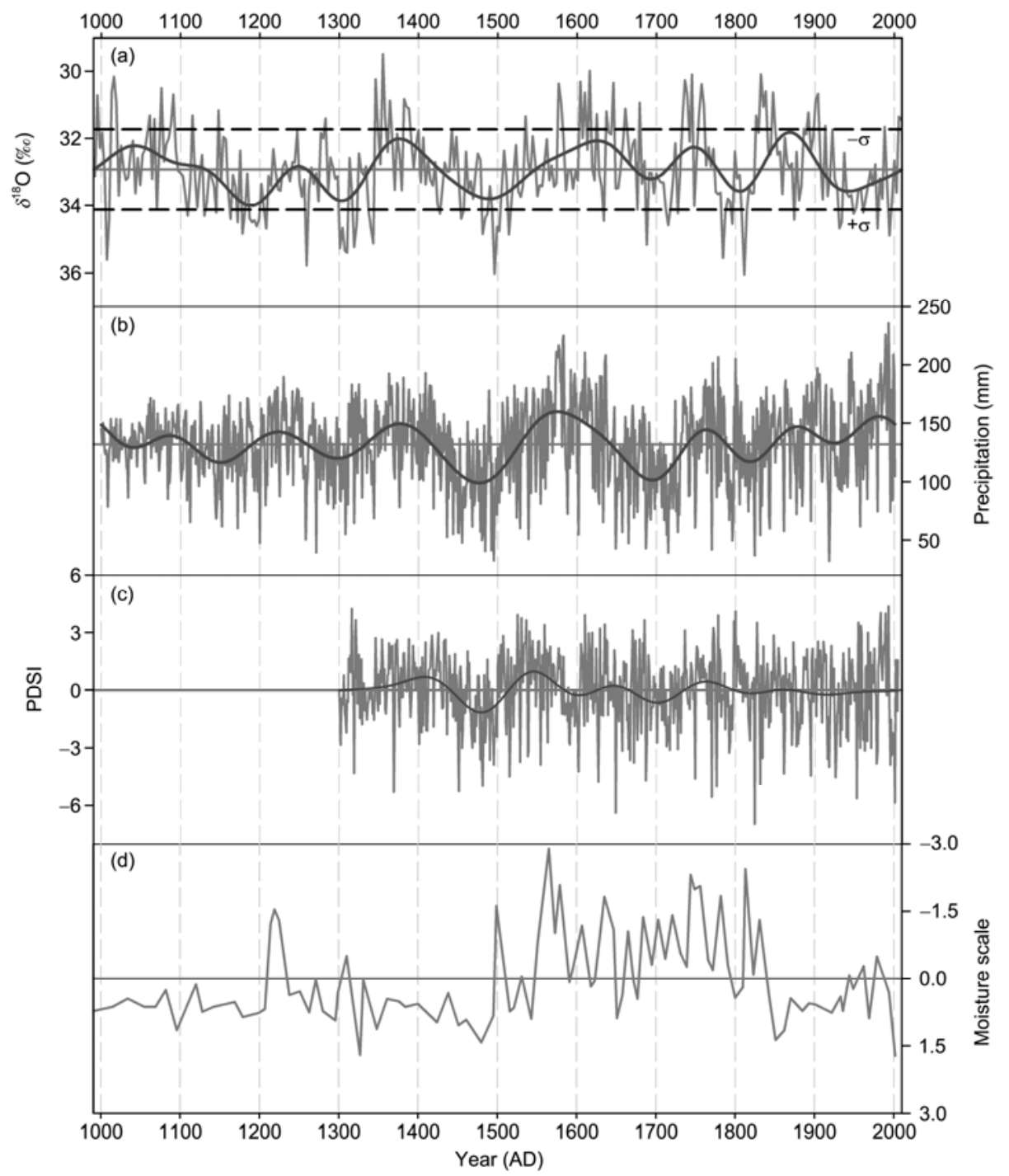

Figure 3 (a) The tree-ring $\delta^{18} \mathrm{O}$ series (3-year temporal resolution) for the Qaidam Basin from AD 991 to 2010 . Horizontal dashed lines denote mean $\pm \sigma$ (one standard deviation). The $y$-axis of $\delta^{18} \mathrm{O}$ values was inverted to facilitate comparisons to other series. (b) Annual-resolution total precipitation series (from the preceding July to the subsequent June) based on the Qaidam Basin tree-ring width data from AD 1000 to 2002 [7]. (c) Annual-resolution summer (June to August) Palmer Drought Severity Index (PDSI) values averaged at four points (as shown in Figure 1 from AD 1300 to 2005 [9]. (d) Millennial low-resolution ( 10 years) effective moisture curve (positive values denote dry conditions) inferred from chironomids in sediments found in the Sugan Lake [5]. The $y$-axis was inverted to facilitate comparisons to other series. Thick horizontal lines denote long-term mean values for all graphs while thick lines denote the smoothed results using a 100-year fast Fourier transform (FFT) filter to emphasize century-scale variation.

that the MCA took place on the Qinghai-Tibetan Plateau between approximately AD 1000 and 1300 followed by the LIA from approximately AD 1350 to 1900 and the rapid warming trend of the Twentieth Century. Patterns of lowfrequency climate variation in the Qaidam Basin show a slight trend towards a drier climate during the MCA, an obvious wet period throughout most of the LIA, and increasing moisture (but at levels that remained lower than the long-term average) during the trend in warming in the Twentieth Century. This pattern has also been documented for the entire arid region of central Asia [21]. Nevertheless, the high-resolution tree-ring $\delta^{18} \mathrm{O}$ record indicates occurrences of shorter drier or wetter periods within these major episodes. For example, during the Eleventh Century, a rela- tively moist stage disrupted the dry MCA trend, whereas prolonged arid intervals occurred from AD 1481 to 1502 and from 1784 to 1814 during the moist LIA. At approximately AD 1340, a period that lies between the MCA and the LIA, a sudden shift towards extremely wet conditions occurred. Similarly, the period flanked by the wet LIA and the Twentieth Century warming trend was also disrupted by an abrupt but brief abnormal interval that took place from AD 1757 to 1784. Accordingly, the high-resolution treering $\delta^{18} \mathrm{O}$ chronology was able to provide evidence for both low-frequency variations and detailed humidity variations throughout the past millennium.

Findings from this study stand in good agreement with previously published annual precipitation series (from the 
preceding July to the subsequent June) on Qaidam Basin [7]. Similar fluctuations within the two high-resolution series (Figure 3(a),(b)) can be interpreted as resulting from the coupling of precipitation and relative humidity. However, there are still some peaks that do not match between the previous precipitation reconstruction and the present isotope series. This is because the $\delta^{18} \mathrm{O}$ chronology represents growing seasonal relative humidity, whereas the reconstructed precipitation represents variation throughout the year [7]. After AD 1920, low-frequency trends in the $\delta^{18} \mathrm{O}$ chronology and the precipitation reconstruction branched in opposite directions. This could be partially explained by increases in both temperature and precipitation, which would not necessarily lead to increased relative humidity [16]. Furthermore, the Twentieth Century trend in increasing precipitation that was shown in the tree-ring width chronology may contain large uncertainties due to the concurrent warming trend [22] and combined $\mathrm{CO}_{2}$ fertilization effect, which would encourage tree growth as a result of rising atmospheric $\mathrm{CO}_{2}$ concentrations [23].

The millennium-scale $\delta^{18} \mathrm{O}$ chronology was also compared to the reconstructed Palmer Drought Severity Index (PDSI) series for summer (June to August), averaged at four points (codes 235, 236, 259, and 260 in Figure 1) in the site investigated for this study (Figure 3(a),(c)) [9]. Figure 3(c) reveals little low-frequency variation in the regional PDSI, and the two time series show little conformity at any frequency component, especially after AD 1800. The reconstructed PDSI chronology was synthesized from several tree-ring width series, which mainly reflect large-scale moisture variations [9], thus weakening the magnitude of low-frequency fluctuations. The $\delta^{18} \mathrm{O}$ series could therefore be more sensitive to centennial climate changes than the PDSI series. In addition, the $\delta^{18} \mathrm{O}$ chronology also matches low-frequency variations in effective moisture in the Sugan Lake sediment chronology, which was reconstructed from data obtained approximately $400 \mathrm{~km}$ west of the current study site [5]. For example, both chronologies show recent droughts, a wet LIA, and a relatively dry MCA (Figure 3(d)). Overall, these comparisons suggest that the tree-ring $\delta^{18} \mathrm{O}$ chronology developed for this study provides an independent and reliable proxy for variations in relative humidity during the past millennium in the extremely arid Qaidam Basin.

A comparison between the tree-ring $\delta^{18} \mathrm{O}$ chronology (Figure 4(a)) and other precipitation-sensitive tree-ring $\delta^{18} \mathrm{O}$ chronologies for the western region of the Qinghai-Tibetan Plateau (Figure $4(\mathrm{~b}) ; 36^{\circ} 35^{\prime} \mathrm{N}, 75^{\circ} 05^{\prime} \mathrm{E}$ ) [12] and the southern region of the Qinghai-Tibetan Plateau (Figure 4(c); $30^{\circ} 18.5^{\prime} \mathrm{N}, 91^{\circ} 35^{\prime} \mathrm{E}$ ) [13] provides evidence by which to evaluate atmospheric circulation patterns that influence the Qaidam Basin climate. The higher levels of fluctuation in our $\delta^{18} \mathrm{O}$ series reveals temporal instability of moisture conditions in our study site, and may indicate that different monsoon regimes control local hydroclimatic variability [15]. Furthermore, pattern similarities between this study's oxygen isotope series and the precipitation series reconstructed for the southern region of the Tibetan Plateau during the Twentieth Century (Figure 4(a),(c)) indicate that the Asian summer monsoon had a dominant influence on Twentieth

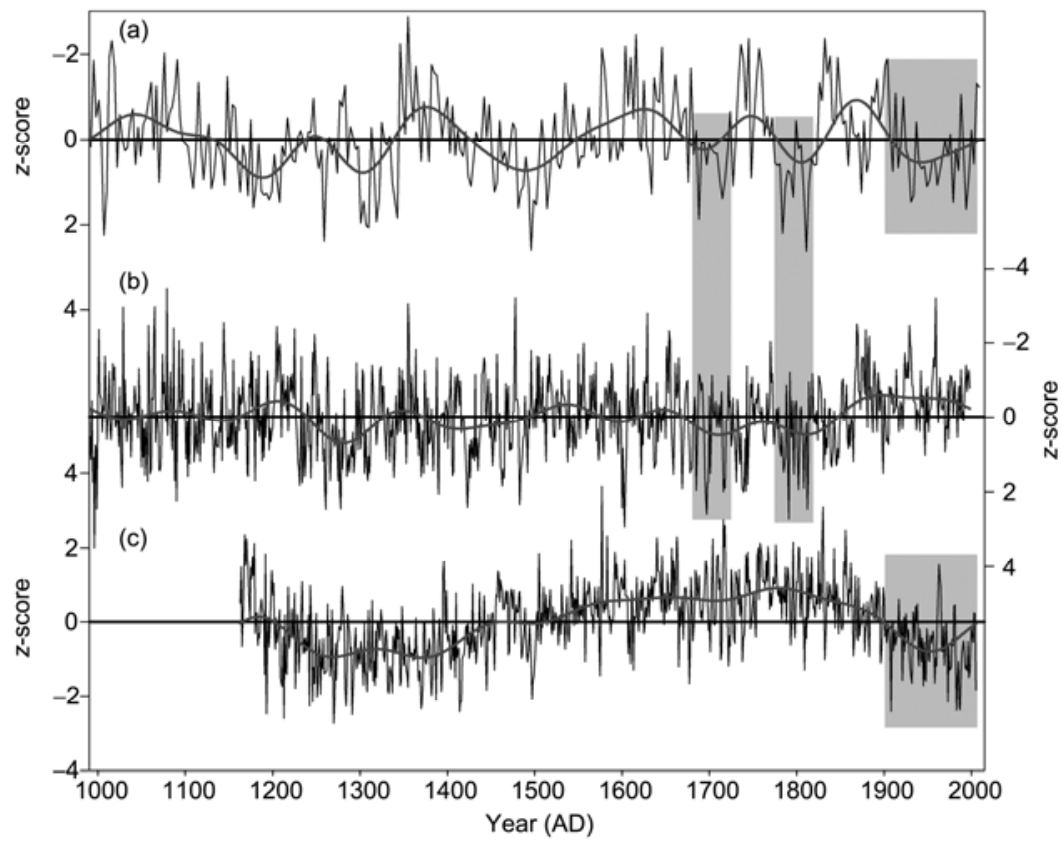

Figure 4 Comparisons between (a) the tree-ring $\delta^{18} \mathrm{O}$ chronology developed for this study and (b) a tree-ring $\delta^{18} \mathrm{O}$ series record of annual precipitation (from the preceding October to the subsequent September) in the western region of the Tibetan Plateau [12], and (c) a summer precipitation reconstruction using the tree-ring $\delta^{18} \mathrm{O}$ chronology reconstructed for the southern region of the Tibetan Plateau [13]. The $y$-axis was inverted in (a) and (b). Values were normalized to $z$-scores and smoothed using 100-year FFT filters. Horizontal lines denote the long-term normalized mean value. 
Century climate patterns in the Qaidam Basin [14]. This circulation pattern was also evident throughout most of the LIA. However, short periods of severe drought, such as those found at the sites investigated for this study, often correspond to the intensification of westerly circulation (e.g. from AD 1673 to 1718 and from AD 1775 to 1814; Figure 4(b)), indicating that westerly circulation had also played an important periodic role in the Qaidam Basin. Thus, the local hydroclimate must have interacted with variations in the relative strengths of both the Asian summer monsoon and westerly circulation, but details of this interaction require further analysis.

\section{Conclusions}

The newly developed millennial chronology with a temporal resolution of 3 years is the longest tree-ring $\delta^{18} \mathrm{O}$ chronology developed for the extremely arid Qaidam Basin, located in the northeastern region of the Qinghai-Tibetan Plateau. This record reveals significant correlations between it and an annual-resolution $\delta^{18} \mathrm{O}$ series developed for the same region from AD 1800 onwards. The Qaidam Basin moisture fluctuations since AD 991 were recorded in the tree-ring $\delta^{18} \mathrm{O}$ series, which can serve as a proxy for relative humidity in the growing season. The low-frequency climate variation pattern in the $\delta^{18} \mathrm{O}$ chronology shows a slight trend towards a drier climate during the MCA, an obvious wet period throughout most of the LIA, and increasing moisture during the trend in warming in the Twentieth Century. The high-resolution tree-ring $\delta^{18} \mathrm{O}$ chronology reflects both lowfrequency variations and shorter-duration fluctuations in humidity. Results from this study generally correspond to precipitation reconstructions based on tree-ring widths and sediments of Sugan Lake. A comparison with the regional PDSI series reveals that the tree-ring $\delta^{18} \mathrm{O}$ chronology is a reliable paleoclimatic proxy that preserves low-frequency data on relative humidity in the arid Qaidam Basin. Moreover, temporal variations in three millennial scale tree-ring $\delta^{18} \mathrm{O}$ series from different regions in the Tibetan Plateau suggest that the Asian summer monsoon and westerly circulation interacted together, and that they jointly influenced the hydroclimate of Qaidam Basin.

We thank Prof. Ian Allison at the Antarctic Climate and Ecosystems Cooperative Research Centre for grammatical editing of the manuscript. This work was supported by the Global Change Research Program of China (2010CB951401) and the National Natural Science Foundation of China (41171167 and 40871002).

1 Liu X D, Chen B D. Climatic warming in the Tibetan Plateau during recent decades. Int J Climatol, 2000, 20: 1729-1742

2 Zhu H F, Zheng Y H, Shao X M, et al. Millennial temperature recon- struction based on tree-ring widths of Qilian juniper from Wulan, Qinghai Province, China. Chin Sci Bull, 2008, 53: 3914-3920

3 Gou X H, Deng Y, Chen F H, et al. Tree ring based streamflow reconstruction for the Upper Yellow River over the past 1234 years. Chin Sci Bull, 2010, 55: 4179-4186

4 Zhang J, Jin M, Chen F, et al. High-resolution precipitation variations in the Northeast Tibetan Plateau over the last 800 years documented by sediment cores of Qinghai Lake. Chin Sci Bull, 2003, 48: 1451-1456

5 Chen J H, Chen F H, Zhang E, et al. A 1000-year chironomid-based salinity reconstruction from varved sediments of Sugan Lake, Qaidam Basin, arid Northwest China, and its palaeoclimatic significance. Chin Sci Bull, 2009, 54: 3749-3759

6 Zhang Q B, Cheng G D, Yao T D, et al. A 2326-year tree-ring record of climate variability on the northeastern Qinghai-Tibetan Plateau. Geophys Res Lett, 2003, 30: 1739-1742

7 Shao X M, Huang L, Liu H B, et al. Reconstruction of precipitation variation from tree rings in recent 1000 years in Delingha, Qinghai. Sci China Ser D-Earth Sci, 2005, 48: 939-949

8 Shao X M, Xu Y, Yin Z Y, et al. Climatic implications of a 3585year tree-ring width chronology from the northeastern Qinghai-Tibetan Plateau. Quat Sci Rev, 2010, 29: 2111-2122

9 Cook E R, Anchukaitis K J, Buckley B M, et al. Asian monsoon failure and megadrought during the last millennium. Science, 2010, 328: 486-489

10 Esper J, Cook E R, Schweingruber F H, et al. Low-frequency signals in long tree-ring chronologies for reconstructing past temperature variability. Science, 2002, 295: 2250-2253

11 Shi C M, Masson-Delmotte V, Risi C, et al. Sampling strategy and climatic implications of tree-ring stable isotopes on the southeast Tibetan Plateau. Earth Planet Sci Lett, 2011, 301: 307-316

12 Treydte K S, Schleser G H, Helle G, et al. The twentieth century was the wettest period in northern Pakistan over the past millennium. Nature, 2006, 440: 1179-1182

13 Grießinger J, Bräuning A, Helle G, et al. Late Holocene Asian summer monsoon variability reflected by $\delta^{18} \mathrm{O}$ in tree-rings from Tibetan junipers. Geophys Res Lett, 2011, 38: L03701

14 Xu G B, Chen T, Liu X H, et al. Potential linkages between the moisture variability on the northeastern Qaidam Basin, China since $1800 \mathrm{AD}$ and the East Asian summer monsoon as reflected by tree-ring $\delta^{18}$ O. J Geophys Res, 2011, 116: D09111

15 Liu X H, Shao X M, Liang E Y, et al. Climatic significance of tree-ring $\delta^{18} \mathrm{O}$ in the Qilian Mountains, northwestern China and its relationship to atmospheric circulation patterns. Chem Geol, 2009, 268: 147-154

16 Wang W Z, Liu X H, Shao X M, et al. A 200 year temperature record from tree ring $\delta^{13} \mathrm{C}$ at the Qaidam Basin of the Tibetan Plateau after identifying the optimum method to correct for changing atmospheric $\mathrm{CO}_{2}$ and $\delta^{13} \mathrm{C}$. J Geophys Res, 2011, 116: G04022

17 McCarroll D, Loader N J. Stable isotopes in tree rings. Quat Sci Rev, 2004, 23: 771-801

18 Roden J S, Lin G H, Ehleringer J R, et al. A mechanistic model for interpretation of hydrogen and oxygen isotope ratios in tree-ring cellulose. Geochim Cosmochim Acta, 2000, 64: 21-35

19 Tian L D, Yao T D, Schuster P F, et al. Oxygen-18 concentrations in recent precipitation and ice cores on the Tibetan Plateau. J Geophys Res, 2003, 108: 4293

20 Yang B, Braeuning A, Johnson K R, et al. General characteristics of temperature variation in China during the last two millennia. Geophys Res Lett, 2002, 29: 1324

21 Chen F H, Chen J H, Holmes J, et al. Moisture changes over the last millennium in arid central Asia: A review, synthesis and comparison with monsoon region. Quat Sci Rev, 2010, 29: 1055-1068

22 Esper J, Frank D, Büntgen U L F, et al. Trends and uncertainties in Siberian indicators of 20th century warming. Glob Change Biol, 2010, 16: $386-398$

23 Soulé P T, Knapp P A. Radial growth rate increases in naturally occurring ponderosa pine trees: A late-20th century $\mathrm{CO}_{2}$ fertilization effect? New Phytol, 2006, 171: 379-390

Open Access This article is distributed under the terms of the Creative Commons Attribution License which permits any use, distribution, and reproduction in any medium, provided the original author(s) and source are credited. 